\title{
Differential Prevalences of Pfmdrl Polymorphisms in Symptomatic and Asymptomatic Plasmodium falciparum Infections in Lastoursville: A Rural Area in East-Central Gabon
}

\begin{abstract}
Steede Seinnat Ontoua (iD ${ }^{1, *}$ Lady Charlene Kouna (D) ${ }^{1} *$ Sandrine Lydie OyegueLiabagui ${ }^{1,2}$ Dominique Fatima VoumboMatoumona $^{3}$ Diamella Nancy Moukodoum ' Romeo Karl Imboumy-Limoukou' Jean Bernard Lekana-Douki ${ }^{1,4}$

'Unité d'Evolution, Epidémiologie et Résistance Parasitaire (UNEEREP), Centre Interdisciplinaire des Recherches Médicales de Franceville (CIRMF) Franceville, BP 769, Gabon; ${ }^{2}$ Ecole Doctorale Régionale d'Afrique Centrale en Infectiologie Tropicale (ECODRAC), Université de Sciences et Techniques de Masuku (USTM), Franceville, BP 876, Gabon; ${ }^{3}$ Départements des Masters/ Licences, Parcours-Types des Sciences Biologiques, Faculté des Sciences et Techniques, Université Marien Ngouabi, Brazzaville, BP 69, Congo; ${ }^{4}$ Département de Parasitologie-Mycologie Médecine Tropicale, Faculté de Médecine, Université des Sciences de la Santé (USS), Libreville, BP 4009, Gabon
\end{abstract}

*These authors contributed equally to this work

Correspondence: Jean Bernard LekanaDouki

UNEEREP-CIRMF, Franceville, B.P. 769,

Gabon

Tel +24l 6252I250; +24I 6259590

Email lekana_jb@yahoo.fr
Purpose: Plasmodium falciparum malaria remains a major public health challenge in subSaharan Africa. Plasmodium falciparum drug resistance mediated by polymorphisms in the Pfmdrl gene contributes to the persistence of the disease on the African continent. This study investigated $P$. falciparum infection features and differences in the Pfmdrl genotypes between symptomatic and asymptomatic malaria cases in a rural area in east-central Gabon. Patients and Methods: A total of 875 children aged from 5 to 185 months were screened for $P$ falciparum infection using Optima-IT ${ }^{\circledR}$ rapid diagnostic tests and standard microscopy. Pfmdr1 polymorphisms at codons 86, 184 and 1246 were investigated using PCR-RFLP.

Results: Among the 448 P. falciparum-infected children, 57.08\% ( $\mathrm{n}=250)$ were symptomatic and $42.92 \%(\mathrm{n}=198)$ were asymptomatic $(p<0.0001)$. In a sub-set of 79 isolates, the Pfmdr1 wild-type N86 was more prevalent in symptomatic (100\%) than in asymptomatic infections $(70.7 \%)(p=0.007)$. The mutant $86 \mathrm{Y}$ and mixed $86 \mathrm{~N} / \mathrm{Y}$ genotypes were observed only in asymptomatic infections. The Y184 and 184F genotype prevalences $(39.1 \%$ vs $19.4 \%$ and $60.9 \%$ vs $80.6 \%$, respectively) were not significantly different between the two groups ( $p=0.097)$. The prevalence of the wild-type D1246 differed significantly between symptomatic $(10.3 \%)$ and asymptomatic $(100 \%)(p<0.0001)$. The NFD and YFD haplotypes were more prevalent in asymptomatic than in symptomatic infections $[(61.9 \%$ vs $31 \% ; p=0.005)$ and $(16.7 \%$ vs $0.0 \% ; p=0.01)]$, whereas the NYD and YYD haplotypes were not significantly different between the two groups [ $21.4 \%$ vs $14.3 \%, p=0.39)$ and $(0.0 \%$ vs $7.1 \%, p=0.24)]$. Conclusion: Our results confirm a high transmission of $P$. falciparum infection in rural Gabon, with a high prevalence of asymptomatic carriage. The higher prevalences of wildtype N86 in symptomatic infections and of D1246 in asymptomatic infections suggest a pathogenicity associated with polymorphisms in Pfmdr1. These results highlight the need to monitor the efficacy of artemisinin-based combination therapies in Gabon.

Keywords: symptomatic malaria, asymptomatic malaria, Pfmdr1, drug resistance, rural Gabon

\section{Introduction}

Plasmodium falciparum malaria is the most important parasitic disease worldwide, and remains a major cause of morbidity and mortality in many developing countries, particularly in sub-Saharan Africa, where the disease remains a major public health problem. In 2019, 215 million (93\%) cases and 384,000 (93,9\%) deaths from malaria were recorded in Africa. ${ }^{1}$ 
Drug resistance is a major cause of the failure for control of malaria, and contributes significantly to the persistence of the disease in Africa and in the world. ${ }^{2}$ The development and spread of Plasmodium falciparum (P. falciparum) resistance to once effective monotherapies such as chloroquine $(\mathrm{CQ})$, pyrimethamine, quinine $(\mathrm{QN})$, cycloguanil has led to a progressive loss of efficacy of these drugs in many endemic countries in Africa and South-East Asia. ${ }^{3,4}$ In the early 2000s, in order to counter the increasing spread of resistant parasites, the World Health Organization (WHO) recommended the use of artemisinin-based combinations therapies (ACTs) for uncomplicated P. falciparum malaria. ${ }^{2}$ This was a leap forward in the goal for control and elimination of malaria in endemic areas. However, a few years later, studies reported cases of therapeutic failures, tolerances and even resistance to artemisinins and partner drugs, notably in South-East Asia countries, ${ }^{5,6}$ where the first resistance to previous antimalarial drugs appeared before spreading through Africa. P. falciparum antimalarial drug resistance, which results in increased parasite clearance time after treatment, ${ }^{6}$ is associated with specific mutations in P. falciparum kelch 13 (Pfk13) propeller gene. Such mutations have not been documented to date in Africa, leading to suspect mutations in other genes to explain AS-AQ and $\mathrm{AL}$ treatment failures reported on the continent, notably polymorphisms in the Pfmdrl gene, 5,7 although the molecular mechanisms of the resistance are still not clear. Single Nucleotide Polymorphisms (SNP) at codons 86, 184, and 1246, the most common in Africa, have been shown to modulate sensitivity and resistance to various antimalarials, including aminoquinolines, arylaminoalcohols and artemisinins. ${ }^{7,8}$ The Pfmdrl N86 genotype has thus been associated with a high risk of artemetherlumefantrine (AL) treatment failure. ${ }^{9}$ Its combination with the $184 \mathrm{~F}$ and D1246 genotypes, which creates the NFD haplotype, was linked to a diminished sensitivity of P. falciparum to mefloquine, lumefantrine and artemisinins, and involved in recrudescent infections after $\mathrm{AL}$ treatment. ${ }^{9}$ In a study carried out in Kenya, early dihydroartemisinin-piperaquine treatment failures were significantly associated with the NFD. ${ }^{10}$ The Pfmdrl YYY haplotype at codons $86 / 184 / 1246$ has been associated with an increased risk of AS-AQ treatment failures. ${ }^{9}$

Furthermore, studies of competitive in vitro culture and manipulation of the Pfmdrl locus by transfection, have shown that the acquisition of these drug resistance genotypes can incur a fitness cost, and that there is an interplay between drug resistance and $P$. falciparum fitness. ${ }^{11,12}$ Other studies suggest that Pfmdrl polymorphisms could potentially influence the virulence of the parasite. ${ }^{13}$

In Gabon, a Central African country, malaria is hyperendemic and $P$. falciparum resistance to drugs, including chloroquine, mefloquine, quinine, artemether has long been documented. ${ }^{14,15}$ In 2003, Gabon adopted the use of ACTs recommended by the WHO in the national malaria control program. This resulted in a significant decline of malaria between 2004 and 2009, ${ }^{16,17}$ although, studies have since shown a trend toward increased malaria in both urban and rural areas. ${ }^{18-21}$ In addition, treatment failures and resistance to antimalarial drugs, including ACTs, were reported. ${ }^{22}$ On the other hand, studies reveal an increased prevalence of Pfmdrl polymorphisms associated with resistance across the country (Franceville, Koula-Moutou, Fougamou, Lastoursville, Dienga). ${ }^{17,20,23}$ However, when we examine these studies, they do not always provide an overview of the prevalence of markers of resistance. Data from the continent indicate that the inclusion of both symptomatic and asymptomatic individuals for assessment of the prevalence may provide a better insight into the prevalence of infection and the distribution of genetic markers of resistance in infected population, especially since some Pfmdrl and Pfcrt genotypes are shown to have a distinct prevalence according clinical status. ${ }^{24,25}$ In Benin, the mutant allele $86 \mathrm{Y}$ and double mutation $76 \mathrm{~T} 86 \mathrm{Y}$ were more represented in asymptomatic group, ${ }^{25}$ whereas in Mali, association between $76 \mathrm{~T}$ and severe malaria had been suggested. ${ }^{26}$

This study aimed to investigate $P$. falciparum infection characteristics and the distribution of Pfmdrl genotypes in symptomatic and asymptomatic malaria in children living in Lastoursville, a rural area in east-central Gabon.

\section{Materials and Methods}

\section{Study Sites and Population}

This study was carried out in Lastourville, and neighboring villages, including Matsatsa, Malende, Mikouyi, and ManaMana, in the Ogooue-Lolo province of east-central Gabon, between March and June 2018 A cohort composed of 401 children aged from 5 to 185 months with fever $\left(\geq 37.5^{\circ} \mathrm{C}\right)$ or a history of fever in the $24 \mathrm{~h}$ before the consultation in health center, and 484 children without fever $\left(<37.5^{\circ} \mathrm{C}\right)$ within the one week before the malaria test and blood sampling, recruited during village visits were screened. Written informed consent 
Table I Sequences of Primer Sets, and Restriction Enzymes Used to Characterize Polymorphisms.I

\begin{tabular}{|c|c|c|c|c|c|c|}
\hline Codons & Primers & $\begin{array}{l}\mathrm{T}\left({ }^{\circ} \mathrm{C}\right) \\
*\end{array}$ & $\begin{array}{l}\text { PCR } \\
\text { Products } \\
\text { (bp) } \#\end{array}$ & $\begin{array}{l}\text { Restriction } \\
\text { Enzyme }\end{array}$ & $\begin{array}{l}\text { Fragment } \\
\text { Lengths } \\
(\text { bp) }\end{array}$ & Genotypes \\
\hline \multirow[t]{2}{*}{86} & \multirow[t]{2}{*}{ A4 -5'AAAGATGGTAACCTCAGTATCAAAGAAGAG3' } & \multirow[t]{2}{*}{57} & \multirow[t]{2}{*}{560} & \multirow[t]{2}{*}{ Apo I } & 250 & N86 \\
\hline & & & & & 505 & $86 Y$ \\
\hline \multirow[t]{2}{*}{184} & \multirow[t]{2}{*}{ A2 -5'GTCAAACGTGCATTTTTTTATTAATGACCATTTA3' } & \multirow[t]{2}{*}{57} & \multirow[t]{2}{*}{560} & \multirow[t]{2}{*}{ Dra I } & $\begin{array}{l}242+204 \\
+173+114\end{array}$ & YI84 \\
\hline & & & & & $\begin{array}{l}242+173 \\
+114\end{array}$ & $184 \mathrm{~F}$ \\
\hline \multirow[t]{4}{*}{1246} & A -5'GGGGGATGACAAATTTTTCAAGATTA3' & \multirow[t]{2}{*}{47} & \multirow[t]{2}{*}{295} & & & \\
\hline & B -5'GGGGGACTAACACGTTTAACATCTT3' & & & & & \\
\hline & DI -5'AATGTAAATGAATTTTCAAACC 3' & \multirow[t]{2}{*}{47} & \multirow[t]{2}{*}{203} & \multirow[t]{2}{*}{ Bgl II } & 203 & I246Y \\
\hline & D2 -5'CATCTTCTCTTCCAАATTTGATA 3' & & & & $113+90$ & DI246 \\
\hline
\end{tabular}

Abbreviations: $* \mathrm{~T}\left({ }^{0} \mathrm{C}\right)$, température $\left({ }^{0} \mathrm{C}\right)$; ${ }^{\#}(\mathrm{bp})$, base pair.

of parents or guardians was obtained. This study was approved by the National Ethics Committee of Gabon and registered under number: $\mathrm{N}^{\circ} 0023 / 2013 / \mathrm{SG} / \mathrm{CNE}$, and conducted in accordance with the Declaration of Helsinki.

\section{Diagnosis}

P. falciparum infection was detected using the Optimal$\mathrm{IT}^{\circledR}$ rapid diagnosis test, completed with microscopy in blood smears, also used to determine the parasite load using Lambarene's method. ${ }^{27}$ Complete Blood Counts (CBCs) were done for children enrolled in Lastoursville medical center, using an automated blood cell counter Yumizen H500 (Horiba Medical, Montpellier, France). Identification of Plasmodium species for mixed or nonfalciparum infections was based on nested polymerase chain reaction (PCR) as previously described. ${ }^{28}$ Monoinfections with non-falciparum species will be excluded from the study.

\section{DNA Extraction}

Genomic DNA was extracted using the Omega Bio-Tek blood DNA E.Z.N.A mini kit according to the manufacturer's protocol. ${ }^{17}$ Briefly, $250 \mu \mathrm{L}$ of blood pellets, $25 \mu \mathrm{L}$ of Omega Bio-Tek (OB) protease $(20 \mathrm{mg} / \mathrm{mL})$ and $250 \mu \mathrm{L}$ of lysis buffer were mixed and heated to $65^{\circ} \mathrm{C}$ for $10 \mathrm{~min}$ before adding 260 $\mu \mathrm{L}$ of ethanol. The mixture was transferred to a mini-column and centrifuged at $10,000 \mathrm{~g}$ for $1 \mathrm{~min}$. The mini-column was washed twice and centrifuged at 10,000 $\mathrm{g}$ for $1 \mathrm{~min}$, then dried at $13,000 \mathrm{~g}$ for $2 \mathrm{~min}$. DNA was eluted with $90 \mu \mathrm{L}$ of distilled water preheated at $65^{\circ} \mathrm{C}$, and kept at $-20{ }^{\circ} \mathrm{C}$ until use.

\section{Analysis of Pfmdrl Polymorphisms}

Polymorphisms in the Pfmdrl gene were determined by PCR-RFLP as previously described. ${ }^{29,30}$ The region flanking codons 86 and 184 was amplified by nested PCR and the region flanking codon 1246 was amplified by a nested PCR following a primary PCR. The primers used are listed in Table 1. Amplification was performed in a total volume of $20 \mu \mathrm{L}$, including $5 \mu \mathrm{L}$ of DNA, $1 \mathrm{X}$ buffer, $1.5 \mathrm{mM} \mathrm{MgCl}_{2}$, $0.2 \mathrm{mM}$ of dNTP (Invitrogen ${ }^{\circledR}$ ), $0.8 \mu \mathrm{M}$ of each primer, and 0.024 units of Taq DNA polymerase (Invitrogen ${ }^{\circledR}$ ), using a $\mathrm{T}_{100}{ }^{\mathrm{TM}}$ thermal cycler (Bio-Rad Laboratories Inc., USA). The cycling program was done as previously described. ${ }^{20}$ PCR products were restricted with specific restriction enzymes: Apo I, Dra I and Bgl II for single nucleotide polymorphisms (SNPs) N86Y, 184FY, and D1246Y, respectively. Digested products were analyzed on $2 \%$ agarose gel containing SYBR Green, separated by electrophoresis and visualized under UV.

\section{Statistical Analysis}

All data were recorded in Microsoft Excel (Office 13). Statistical analyzes were carried out with GraphPad Prism ${ }^{\circledR}$ software version 7.00. Age was expressed as the mean and standard deviation (SD), and parasite density as the geometric mean (GM) and range. Each allele of mixedgenotype infection was included for the construction of 
Table 2 Characteristics of the Study Population

\begin{tabular}{|c|c|c|c|}
\hline & Infected $(N=448)$ & Uninfected $(N=427)$ & $p$ \\
\hline \multicolumn{4}{|l|}{ General characteristics } \\
\hline Sex ratio $(M / F)^{\#}$ & 1.005 & I.I & 0.57 \\
\hline Mean age \pm SD* (months) & $58.8 \pm 47.9$ & $64.1 \pm 50.4$ & 0.26 \\
\hline Mean temperature $\pm \mathrm{SD} *\left({ }^{\circ} \mathrm{C}\right)$ & $36.94 \pm 1.04$ & $36.57 \pm 0.76$ & $<0.0001$ \\
\hline Hemoglobin $\pm S D^{*}(\mathrm{~g} / \mathrm{dl})$ & $7.20 \pm 1.84$ & $8.83 \pm|8| 1$ & $<0.0001$ \\
\hline Red blood cell \pm SD* $\left(\times 10^{6} / \mu \mathrm{L}\right)$ & $3.12 \pm 0.95$ & $3.88 \pm 0.074$ & $<0.000$ I \\
\hline White blood cell \pm SD* $\left(\times 10^{3} / \mu \mathrm{L}\right)$ & $9,8 \pm 4.89$ & $12.88 \pm 7.57$ & 0.0036 \\
\hline Platelets $\pm \mathrm{SD}^{*}\left(\times 10^{3} / \mu \mathrm{L}\right)$ & $168.4 \pm 127.6$ & $217.7 \pm 100.5$ & $<0.0001$ \\
\hline
\end{tabular}

Abbreviations: ${ }^{*} \mathrm{M} / \mathrm{F}$, male/female; *SD, standard deviation.

haplotype. The Chi-square test was used to compare the categorical variables among the groups. The nonparametric Mann Whitney $U$-test and Fisher's exact test were used for group comparisons, as appropriate. Statistical significance was defined at $p$-value $<0.05$.

\section{Results}

\section{Study Population}

Of the 885 children tested, ten were excluded for P. malariae mono-infections. In total, 875 children were included in this study. Ages were recorded for only 836 children. The general characteristics of the study population are reported in Table 2 . The mean age of the children was $60.8 \pm 48.9$ months, and the male/female sex ratio was 1.05. In the children cohort, $51.2 \%$ (448/875) were infected by $P$. falciparum and $48.8 \%$ (427/875) were uninfected. In $P$. falciparum infected group, $11.4 \%$ (51/448) were co-infected with Plasmodium malariae. The proportion of infected children was significantly higher in febrile children $(250 / 400,62.5 \%)$ than in afebrile children (198/ $475,41.7 \%), \mathrm{p}<0.0001$. Overall, the mean age was not significantly different between infected and uninfected (64.1 months against 58.8 months, $p=0.26$ ). The values of hemoglobin, red blood cells, white blood cells and platelets were significantly lower in plasmodium-infected children $\left(7.20 \mathrm{~g} / \mathrm{dl}, 3.12 \times 10^{6} / \mu \mathrm{L}, 9.8 \times 10^{3} / \mu \mathrm{L}, 168.4 \times 10^{3}\right.$ $/ \mu \mathrm{L}$, respectively) than in uninfected children $(8.83 \mathrm{~g} / \mathrm{dl}$, $3.88 \times 10^{6} / \mu \mathrm{L}, 12.88 \times 10^{3} / \mu \mathrm{L}, 217.7 \times 10^{3} / \mu \mathrm{L}$, respectively; $p<0.0001)$.

\section{P. falciparum Infection Parameters}

Among the 448 P. falciparum-infected children, symptomatic $(55.80 \%)$ was more common than asymptomatic carriers $(44.20 \%)(p=0.0005)$. The characteristics of the two parasitemia are reported in Table 3 . The mean age of symptomatic children was significantly lower than asymptomatic children (34.3 months vs 86.2 months, $p<$ $0.0001)$. Parasite density was significantly higher in symptomatic than asymptomatic infections $(p=0.0051)$. Due to financial issues, hematological parameters were only available for malaria cases. According to age group, as shown in Table 3, children aged under 60 months were the most affected by $P$. falciparum infection (64.79\%, $p<0.0001)$. Symptomatic malaria was also more common in children aged under 5 years old $(90.39 \%, p<0.0001)$, mainly in those aged $\leq 24$ months (49.8\%, $p<0.0001)$, while asymptomatic infection was more common in children over 5 years old $(64.97 \%, p<$ $0.0001)$.

\section{Prevalence of Pfmdr I Gene SNPs}

Among the 448 isolates of $P$. falciparum extracted from infected children, 79 isolates (29 from symptomatic infections and 50 from asymptomatic infections) were genotyped for SNPs at codons 86, 184, and 1246 of the Pfmdr1 gene.

Out of the isolates genotyped, 79.7\% (63/79), 74.7\% $(59 / 79)$ and $89.9 \%(71 / 79)$ were successfully genotyped for N86Y, 184FY and D1246Y SNPs, respectively.

The distribution of SNPs at codons 86, 184 and 1246 of Pfmdr1 gene for each group of infected children is summarized in Table 4. The N86 genotype was significantly more frequent in symptomatic infections $(22 / 22,100 \%)$ than in asymptomatic infections $(29 / 41,70.7 \%)(p=0.007)$. In asymptomatic infections, the frequency of the combined wild-type and mixed genotypes (N86 $+86 \mathrm{~N} / \mathrm{Y})$ was $76.9 \%$ (40/52), but remained lower than the frequency of the N86 genotype observed in symptomatic infections $(100 \%)(p=0.014)$. The prevalence of mutant and mixed genotypes combined $(86 \mathrm{Y}+$ 
Table 3 Comparison of Symptomatic versus Asymptomatic Infected Children Sociodemographic and Biological Features

\begin{tabular}{|c|c|c|c|}
\hline & Symptomatic infected $(\mathrm{N}=250)$ & Asymptomatic infected $(\mathrm{N}=198)$ & $\mathbf{p}$ \\
\hline \multicolumn{4}{|l|}{ General characteristics } \\
\hline Sex ratio $(M / F)$ & 1.29 & 0.74 & 0.0045 \\
\hline Mean age $\pm S D^{*}$ (month) & $34.3 \pm 31.05$ & $86.2 \pm 47.97$ & $<0.0001$ \\
\hline Mean temperature $\pm \mathrm{SD} *\left({ }^{\circ} \mathrm{C}\right)$ & $37.79 \pm 1.048$ & $36.46 \pm 0.639$ & $<0.0001$ \\
\hline Geometric Parasitemia (parasites $/ \mu \mathrm{L}$ ) & $782 \mid(3727-16,414)$ & $2825(2269-3517)$ & 0.0051 \\
\hline Hemoglobin $\pm S D *(g / d l)$ & $7.196 \pm 1.841$ & ND & ND \\
\hline Red blood cell $\pm S D^{*}(\times 106 / \mathrm{mm} 3)$ & $3.107 \pm 0.947$ & ND & ND \\
\hline White blood cell \pm SD* $(\times 103 / \mathrm{mm} 3)$ & $9.8 \pm 4.886$ & ND & ND \\
\hline Platelets \pm SD* $(\times 103 / \mathrm{mm} 3)$ & $168.4 \pm 127.6$ & ND & ND \\
\hline Age group & Symptomatic infected $[\mathrm{n} / \mathrm{N},(\%)]$ & Asymptomatic infected $[\mathrm{n} / \mathrm{N},(\%)]$ & $p$ \\
\hline$\leq 24$ months & $114 / 229(49.8 \%)$ & 16/197 (8.1\%) & $<0.0001$ \\
\hline$>24-48$ months & $81 / 229(35.4 \%)$ & $40 / 197$ (20.3\%) & 0.0006 \\
\hline$>48-60$ months & $12 / 229(5.2 \%)$ & $13 / 197$ (6.6\%) & 0.68 \\
\hline$>60-120$ months & $13 / 229(5.7 \%)$ & $80 / 197$ (40.6\%) & $<0.0001$ \\
\hline$>120$ months & $9 / 229$ (3.9\%) & $48 / 197$ (24.4\%) & $<0.0001$ \\
\hline$p$ & $<0.0001$ & $<0.0001$ & \\
\hline
\end{tabular}

Abbreviations: *SD, standard deviation; M/F, male/female; ND, not determined.

$86 \mathrm{~N} / \mathrm{Y}$ ) was higher in asymptomatic infections than in symptomatic infection ( $23.1 \%$ vs $0.0 \%, p=0.014)$.

For codon 184, there was no significant difference in wild-type $184 \mathrm{Y}$ prevalence between symptomatic and asymptomatic infections ( $39.1 \%$ vs $19.4 \%, p=0.097$ ), as well as the mutant $184 \mathrm{~F}(60.9 \%$ vs $80.6 \%, p=0.097)$. A higher frequency of mutant $184 \mathrm{~F}$ compared to wild-type $184 \mathrm{Y}$ was observed in asymptomatic cases $(80.6 \%$ vs $19.4 \%, p<0.0001$ ), whereas in symptomatic infections, the frequencies of wild-type and mutant genotypes were not significantly different $(39.1 \%$ vs $60.9 \%, p=0.24)$ (Table 4$)$.

The prevalence of wild-type D1246 genotype was significantly higher in asymptomatic than in symptomatic cases $(100 \%$ vs $10.3 \%, p<0.0001)$, whereas the $1246 \mathrm{D} /$ $\mathrm{Y}$ mixed genotype prevalence was more high in symptomatic than in asymptomatic infections $(89.7 \%$ vs $0.0 \%$, $p<0.0001$ ) (Table 4).

\section{Haplotype Prevalences}

Based on three Pfmdrl codons (86, 184 and 1246), including mixed-genotype infections, six haplotypes were identified: NFD, NYD, YFD, YYD, NFY, and NYY (Figure 1).

The prevalences of each haplotype in symptomatic and asymptomatic infections were compared, and are resumed in Figure 1. NFD was significantly most frequent in asymptomatic than in symptomatic infections $(p=0.0045)$. The prevalence of the NYD haplotype was not significantly different between the two groups: symptomatic $(9 / 42,21.4 \%)$, and asymptomatic (6/42, 14.3\%) $(p=0.39)$. The NFY, NYY, YFD and YYD haplotypes were not all present in both groups simultaneously. NFY and NYY haplotypes were more frequently identified in symptomatic than in asymptomatic cases $(26.2 \%$ vs $0.0 \%$, $p=0.0005$ and $21.4 \%$ vs $0.0 \%, p=0.002$, respectively), while YFD (16.7\%) and YYD (7.1\%) were only identified in plasmodial isolates from asymptomatic infections.

\section{Discussion}

The present study examines the prevalence of P. falciparum infections and investigates the Pfmdrl genetic profile of $P$. falciparum isolates in symptomatic and asymptomatic infections in a rural endemic setting in Gabon.

This study shows a high prevalence of $P$. falciparum infection in the Lastoursville area, as observed and described in other rural areas of the country, ${ }^{18,31}$ as well as in other endemic areas across the continent. ${ }^{32,33}$ The proportion of malaria in febrile children here is higher than that previously recorded in Franceville in an urban setting. ${ }^{34}$ This confirms a sustained transmission of $P$. falciparum infection in rural Gabon. Poor socioeconomic status, environmental conditions and limited knowledge about malaria and prevention measures are often cited as reasons for the high prevalence of 
Table 4 Genotype Distribution in Symptomatic and Asymptomatic Infections

\begin{tabular}{|c|c|c|c|c|c|}
\hline \multirow[t]{2}{*}{ Codon } & \multirow[t]{2}{*}{ Genotype } & \multirow[t]{2}{*}{ Total } & \multicolumn{2}{|c|}{ Prevalence $[n / N(\%)]$} & \multirow[t]{2}{*}{$p$} \\
\hline & & & Symptomatic & Asymptomatic & \\
\hline 86 & $\begin{array}{l}N \\
Y \\
N / Y \text { (mixed) }\end{array}$ & $\begin{array}{l}5 \mathrm{I}(8 \mathrm{I} .0 \%) \\
\mathrm{I}(\mathrm{I} .6 \%) \\
\mathrm{II}(\mathrm{I} .4 \%)\end{array}$ & $\begin{array}{l}22 / 22(100 \%) \\
0 \\
0\end{array}$ & $\begin{array}{l}29 / 4 \mathrm{I}(70.7 \%) \\
\mathrm{I} / 4 \mathrm{I}(2.5 \%) \\
\text { II/4I (26.8\%) }\end{array}$ & $\begin{array}{l}0.007 \\
1 \\
0.006\end{array}$ \\
\hline 184 & $\begin{array}{l}Y \\
F \\
Y / F \text { (mixed) }\end{array}$ & $\begin{array}{l}16(27.1 \%) \\
43(72.9 \%) \\
0.0\end{array}$ & $\begin{array}{l}9 / 23(39.1 \%) \\
14 / 23(60.9 \%) \\
0\end{array}$ & $\begin{array}{l}7 / 36(19.4 \%) \\
29 / 36(80.6 \%) \\
0\end{array}$ & $\begin{array}{l}0.097 \\
0.097 \\
\text { ND }\end{array}$ \\
\hline 1246 & $\begin{array}{l}D \\
Y \\
D / Y \text { (mixed) }\end{array}$ & $\begin{array}{l}45(63.4 \%) \\
0.0 \\
26(36.6 \%)\end{array}$ & $\begin{array}{l}3 / 29(10.3 \%) \\
0 \\
26 / 29(89.7)\end{array}$ & $\begin{array}{l}42 / 42(100 \%) \\
0 \\
0\end{array}$ & $\begin{array}{l}<0.0001 \\
I \\
<0.0001\end{array}$ \\
\hline
\end{tabular}

Abbreviation: ND, Not Determined.

plasmodial infections in rural areas. ${ }^{18,20}$ However, this prevalence is lower than that described four years ago in the region. ${ }^{20}$ Studies show that, despite the socioeconomic status and environmental conditions, better knowledge on prevention and treatment measures has helped to reduce malaria incidence. ${ }^{21,35}$

The mean ages of infected and uninfected children were not significantly different, contrary to previous findings in the region ${ }^{20}$ and other areas in country. ${ }^{34}$ Furthermore, an overall decrease in hematological parameters was observed in infected children. This confirms the significant negative impact of $P$. falciparum infection on these parameters, as demonstrated in a previous study carried out in Kenya. ${ }^{36}$ Indeed, it is known that this decrease, a common hallmark in plasmodial infections, is accentuated during infections involving $P$. falciparum due to the high parasitemia and induced immune response.

P. falciparum infection was more common in symptomatic children than in asymptomatic. This is consistent with the results of a study carried out in Ota, South west Nigeria $^{37}$ and contradicts the findings of another study conducted in Nigeria, in Aba town. ${ }^{32}$ Furthermore, the prevalence of asymptomatic carriage in the present study (22.63\% in the study population and $44.20 \%$ among infected children) was higher than previously described across the country ${ }^{31,38}$ and on the continent, particularly in Lubumbashi in the Democratic Republic of the Congo $(16 \%)^{39}$ and Aba in Nigeria $(33.1 \%),{ }^{32}$ although higher prevalences $(57.3 \%$ and $45.9 \%)$ were reported in Ota in southwestern Nigeria ${ }^{37}$ and in Dienga in southeastern

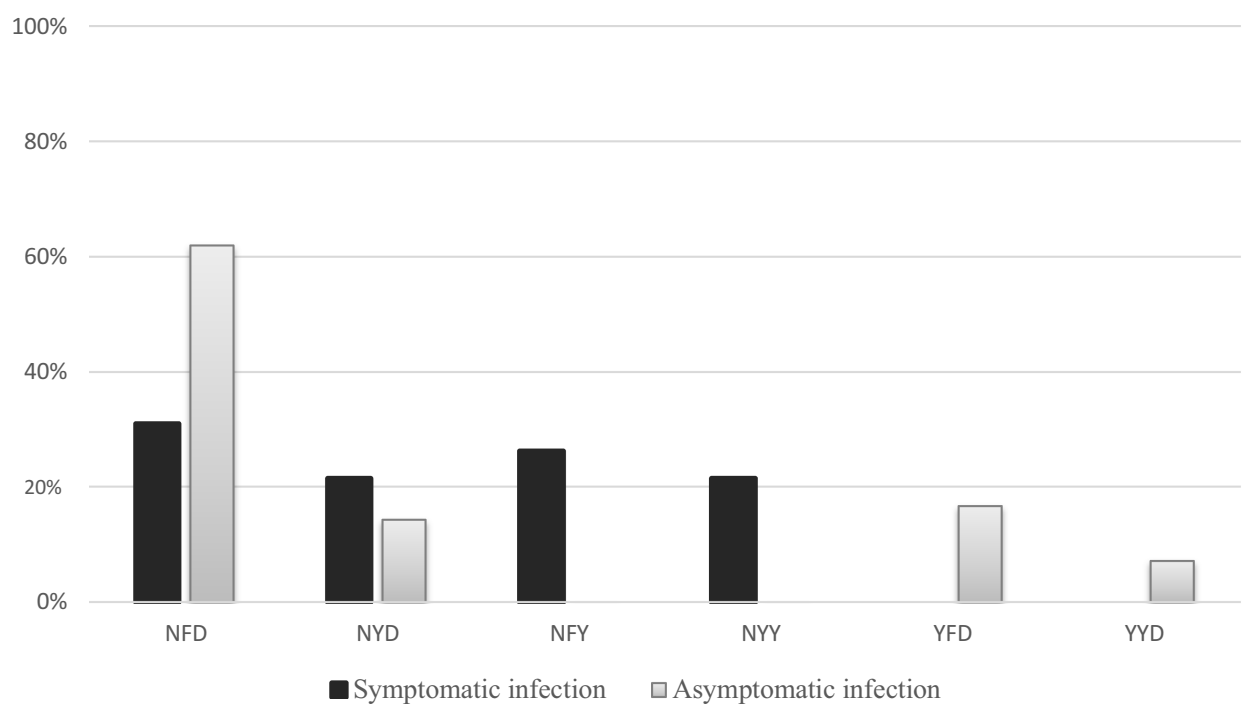

Figure I Haplotypes distribution in symptomatic and asymptomatic infections. 
Gabon, ${ }^{21}$ respectively. Altogether, these studies show a high prevalence of asymptomatic carriage in rural areas in sub-Saharan Africa.

The mean age of febrile children was significantly lower than that of asymptomatic children. These results are similar to those obtained elsewhere on the continent. ${ }^{24,32}$ According to age groups, children aged from 0 to 48 months were the most affected by malaria, as opposed to previous results in urban areas where children over five years old were the most affected. ${ }^{19,20}$ Host-specific immune status being the main determinant in the progression from Plasmodium infection to the disease stage, ${ }^{40}$ these findings may reflect insufficient premunition to malaria, and explain why children under five years old remain priority targets of malaria prevention and control campaigns worldwide. In our study, children aged over 60 months were mostly asymptomatic, which is consistent with results found in Uganda, ${ }^{40}$ Nigeria $^{32}$ and Tanzania. ${ }^{41}$ Overall, data revealed an increasing prevalence of asymptomatic carriage with age, confirming a strong effect of age on the development of immunity to malaria, which includes both anti-disease immunity (ability to tolerate an infection without developing symptoms) and anti-parasite immunity (ability to control parasite densities), as established in Uganda. ${ }^{40}$ This may explain the lower parasite density observed in asymptomatic children compared to febrile children in this study. Asymptomatic status is related with maintaining a low parasite density which in turn contributes to the stimulation of immunity. This situation highlights a balance between parasite and host.

This study is the first to compare the prevalence levels of SNPs in the Pfmdrl gene in symptomatic and asymptomatic $P$. falciparum infections in rural Gabon. Data reveals high prevalences of N86, 184F and D1246 alleles in comparison to the $86 \mathrm{Y}, \mathrm{Y} 184$, and $1246 \mathrm{Y}$ alleles. Similar results were previously reported in Gabon, ${ }^{20,23}$ as well as in Nigeria ${ }^{37}$ and Burkina-Faso. ${ }^{42}$ A Kenyan study associated the increased prevalence of CQ-susceptible N86 and D1246 alleles, and the corresponding decline of the CQresistance-associated Pfmdr1 mutations $86 \mathrm{Y}$ and $1246 \mathrm{Y}$, with CQ withdrawal 19 years earlier. ${ }^{43}$ Elsewhere, the cessation of $\mathrm{CQ}$ use resulted in a fast reexpansion of the diverse population of CQ-susceptible parasites. $^{44}$ However, the high prevalence in Pfmdrl N86, 184F and D1246 alleles observed in this study may not necessarily only be due to the withdrawal of $\mathrm{CQ}$, but could also, in large part, be explained by the introduction of AL as firstline treatment. Indeed, there is evidence that the selection of Pfmdr1 N86, 184F, and D1246 is primarily driven by exposure to AL. A study conducted in the Bagamoyo district, Tanzania, associated the selection of genotypes N86, 184F, and D1246 much more strongly with the introduction of AL than with CQ removal. ${ }^{45}$ Similarly, an increase in the prevalence of CQ-susceptible N86 allele was observed in Franceville, Gabon, only five years after replacing CQ with AL and Artesunate-Mefloquine. ${ }^{17}$ This finding, our study and other previous works ${ }^{20}$ suggest that the efficacy of AL in the treatment of uncomplicated malaria could be threatened in Gabon, since wild-type N86 and D1246 have been strongly associated with a decrease in parasite susceptibility to AL. ${ }^{9,46}$

In symptomatic infections, a higher prevalence of wildtype Pfmdr1 N86 was found, while mutant genotype $86 \mathrm{Y}$ was more prevalent in asymptomatic infections. No $86 \mathrm{Y}$ mutant genotype was found in plasmodial isolates from febrile children, whereas it was present in isolates from asymptomatic children. Similar results were found in Benin $^{25}$ and in Uganda. ${ }^{13,24}$ Altogether, these results suggest that children infected with $P$. falciparum harboring wild-type N86 would be more likely to develop fever, or that parasites with Pfmdr1 N86 would have a greater ability to cause symptoms, thus supporting the hypothesis of genotype-related virulence of $P$. falciparum, ${ }^{13}$ although this has not yet been clearly demonstrated. The high prevalence of Pfmdr1 N86 and the concomitant absence of $86 \mathrm{Y}$ in febrile children, could also be due to prior ALtreatment (self-medication), which is known to quickly eliminate susceptible parasites and select parasites with the N86 allele soon after therapy. ${ }^{9}$ Self-medication is a common practice in Gabon, ${ }^{21}$ and it is not rare that a delay of one to several days (conducive to the practice) occurs between symptom onset and consultation. ${ }^{34}$ However, this hypothesis could be nuanced due to the significant presence of the AL-sensitive Pfmdr1 $1246 \mathrm{Y}$ mutation in children with malaria.

The higher prevalence of the wild-type D1246 in asymptomatic individuals found in our study differs from that found in Uganda $^{24}$ where the wild-type D1246 was more prevalent in symptomatic individuals than in asymptomatic individuals. The AL pressure, known to select for prolonged selection of this genotype, up to two months after treatment with $\mathrm{AL},{ }^{47}$ could explain the result in our study. The significantly higher frequencies of D1246 and $86 \mathrm{Y}$ genotypes in asymptomatic infections than in symptomatic infections, may also reflect fitness advantages for parasites harboring these genotypes when selective drug pressure is low or absent. ${ }^{11,12}$ 
The data showed no significant difference in the distribution of each of the Y184 and 184F genotypes in symptomatic and asymptomatic infections. Furthermore, the mutant 184F genotype was the most common genotype in both groups. This result is consistent with previous findings. ${ }^{20}$ The high frequency of the Pfmdrl 184F mutation reinforces the above hypothesis of a wider and easier access to ACTs (AL and ASAQ). This genotype has been associated with a high risk of treatment failure. ${ }^{48}$ It is also known to be selected in reinfections up to 40 days after AL treatment. ${ }^{47}$ However, unlike the two previous codons ( 86 and 1246), polymorphisms at codon 184 are considered to be minor modulators of the parasite's tolerance to ACTs. ${ }^{49}$

Out of the six haplotypes identified in the present study and circulating in the region, NFD was the most frequent, followed by NYD; the other haplotypes (NFY, NYY, YFD and YYD, in decreasing order) were the least prevalent. These results corroborate previous data obtained in this region. ${ }^{20}$ Our results confirm a strong use of $\mathrm{AL}$, as suggested by the results from Tanzania, which associated a significant selection of NFD and NYD after the implementation of ACTs five years earlier. ${ }^{45}$ A similar trend was observed in five other African countries including Comoros, Swaziland, Kenya, Tanzania and Uganda, which use AL as first-line treatment. ${ }^{50}$ The high prevalence of NFD is an early warning sign of impaired future AL efficacy. Indeed, a trend of decreased susceptibility of $P$. falciparum to lumefantrine related to haplotypes has been shown, in decreasing order from NFD, NYD, YYY, to YYD. Moreover, parasites carrying the NFD haplotype are able to resist to lumefantrine blood concentrations 15 -fold higher than the concentrations tolerated by parasites with the YYY haplotype. ${ }^{49}$ Close monitoring of therapeutic efficacy of drugs in clinical use is therefore needed. Furthermore, the absence of the YYY haplotype here confirms the decrease in CQ selective pressure.

The data found in this study confirm a stronger selection of parasites carrying the wild-type Pfmdrl haplotype in asymptomatic infections than in symptomatic infections, marked by a significantly higher prevalence of NFD haplotype in asymptomatic than in symptomatic infections. In an Australian study, it has been suggested that in areas where malaria treatment includes mefloquine and lumefantrine, parasites with wild-type $P f m d r 1$ alleles could have advantages in terms of both fitness and decreased drug susceptibility with respect to parasites with Pfmdrl mutants alleles. ${ }^{12}$ These results are worrisome because they suggest that the fitness benefits of parasites harboring less drug-sensitive genotypes may promote progression to the symptomatic stage. In addition, the high presence of parasites with these genotypes in asymptomatic infections, which are rarely treated or left untreated, favors their survival and transmission within the community. This shows the importance of continued monitoring and characterization of molecular markers of resistance in parasites circulating in symptomatic and asymptomatic infections. It would provide an overview of the spread of these genetic markers in infected populations in order to adjust intervention strategies to reduce outbreaks of disease transmission. It should be noted that drug use with parental supervision could, nevertheless, help to limit treatment failures in children, ${ }^{51}$ and thus selection of resistance-mediated genotypes.

\section{Conclusion}

This study confirms a high prevalence of $P$. falciparum infection among children in rural Gabon, with a high prevalence of asymptomatic carriage, which serves as a reservoir and maintains the parasite's transmission in the community. The prevalence of the Pfmdrl wild-type $86 \mathrm{~N}$ genotype was significantly higher in febrile children, whereas Pfmdrl D1246 was significantly more frequent in asymptomatic children. A virulence potentially related to the genotype of the parasite, previous antimalarial therapy, or host immune status are factors that may explain these differences. However, additional studies are needed with larger sampling sizes, including other epidemiological settings and resistance-mediated genes. Polymorphisms in these resistance-mediated genes combined with polymorphisms in Pfmdrl gene could contribute to a greater virulence of the parasite and/or even higher-levels of resistance to the current national malaria regimen in Gabon.

\section{Acknowledgments}

We wish to thank the children and parents who gave their consent to participate in the study. We are also grateful to the staff of the pediatric wards of the Lastourville Health Center for their support.

\section{Funding}

This work was supported by European and Developing Countries Clinical Trials Partnership (EDCTP).

\section{Disclosure}

The authors declare that they have no conflicts of interests for this work. 


\section{References}

1. World Health Organization. World Malaria Report 2020. Vol. 299. World Health Organization; 2020.

2. World Health Organization. Guidelines for the Treatment of Malaria. World Health Organization; 2006.

3. Le Bras J. Chimiorésistance de Plasmodium falciparum. Médecine Mal Infect. 1999;29:S274-S281. doi:10.1016/S0399-077X(00)88264-5

4. Jelinek T, Schelbert P, Löscher T, Eichenlaub D. Quinine resistant falciparum malaria acquired in east Africa. Trop Med Parasitol Off Organ Dtsch Tropenmedizinische Ges Dtsch Ges Tech Zusammenarbeit GTZ. 1995;46:38-40.

5. Ashley EA, Dhorda M, Fairhurst RM, et al. Spread of artemisinin resistance in Plasmodium falciparum Malaria. $N$ Engl $J$ Med. 2014;371:411-423. doi:10.1056/NEJMoa1314981

6. Dondorp AM, Nosten F, Yi P, et al. Artemisinin resistance in plasmodium falciparum malaria. $N$ Engl $J$ Med. 2009;361(5):455-467. doi:10.1056/NEJMoa0808859

7. Duraisingh MT, Cowman AF. Contribution of the pfmdr1 gene to antimalarial drug-resistance. Acta Trop. 2005;94:181-190. doi:10.1016/j.actatropica.2005.04.008

8. Reed MB, Saliba KJ, Caruana SR, Kirk K, Cowman AF. Pgh1 modulates sensitivity and resistance to multiple antimalarials in Plasmodium falciparum. Nature. 2000;403(6772):906-909. doi: $10.1038 / 35002615$

9. Venkatesan M, Gadalla NB, Stepniewska K, et al. Polymorphisms in Plasmodium falciparum Chloroquine Resistance Transporter and Multidrug Resistance 1 Genes: parasite Risk Factors that Affect Treatment Outcomes for P. falciparum Malaria after Artemether-Lumefantrine and Artesunate-Amodiaquine. Am J Trop Med Hyg. 2014;91:833-843. doi:10.4269/ajtmh.14-0031

10. Henriques G, Hallett RL, Beshir KB, et al. Directional Selection at the pfmdr1, pfcrt, pfubp1, and pfap2mu Loci of Plasmodium falciparum in Kenyan Children Treated With ACT. J Infect Dis. 2014;210:2001-2008. doi:10.1093/infdis/jiu358

11. Ochong E, Tumwebaze P, Byaruhanga O, Greenhouse B, Rosenthal P. Fitness Consequences of Plasmodium falciparum pfmdr1 Polymorphisms Inferred from Ex Vivo Culture of Ugandan Parasites. Antimicrob Agents Chemother. 2013;57:4245-4251. doi:10.1128/AAC.00161-13

12. Hayward R, Saliba KJ, Kirk K. pfmdr1 mutations associated with chloroquine resistance incur a fitness cost in Plasmodium falciparum. Mol Microbiol. 2005;55:1285-1295. doi:10.1111/j.13652958.2004.04470.x

13. Tukwasibwe S, Tumwebaze $\mathrm{P}$, Conrad $\mathrm{M}$, et al. Drug resistance mediating Plasmodium falciparum polymorphisms and clinical presentations of parasitaemic children in Uganda. Malar J. 2017;16:125. doi:10.1186/s12936-017-1777-0

14. Ndong JMM, Atteke C, Aubouy A, et al. In vitro activity of chloroquine, quinine, mefloquine and halofantrine against Gabonese isolates of Plasmodium falciparum. Trop Med Int Health. 2003;8:25-29. doi:10.1046/j.1365-3156.2003.00967.x

15. Pradines B, Mamfoumbi MM, Parzy D, et al. In vitro susceptibility of Gabonese wild isolates of Plasmodium falciparum to artemether, and comparison with chloroquine, quinine, halofantrine and amodiaquine. Parasitology. 1998;117:541-545. doi:10.1017/S0031182098003400

16. Bouyou-Akotet MK, Mawili-Mboumba DP, Kendjo E, et al. Evidence of decline of malaria in the general hospital of Libreville, Gabon from 2000 to 2008. Malar J. 2009;8:300. doi:10.1186/1475-2875-8-300

17. Lekana-Douki JB, Boutamba SDD, Zatra R, et al. Increased prevalence of the Plasmodium falciparum Pfmdr1 $86 \mathrm{~N}$ genotype among field isolates from Franceville, Gabon after replacement of chloroquine by artemether-lumefantrine and artesunate-mefloquine. Infect Genet Evol. 2011;11:512-517. doi:10.1016/j.meegid.2011.01.003
18. Assele V, Ndoh GE, Nkoghe D, Fandeur T. No evidence of decline in malaria burden from 2006 to 2013 in a rural Province of Gabon: implications for public health policy. BMC Public Health. 2015;15 (1):81. doi:10.1186/s12889-015-1456-4

19. Mawili-Mboumba DP, Akotet MKB, Kendjo E, et al. Increase in malaria prevalence and age of at risk population in different areas of Gabon. Malar J. 2013;12:3. doi:10.1186/1475-2875-12-3

20. Maghendji-Nzondo S, Kouna L-C, Mourembou G, et al. Malaria in urban, semi-urban and rural areas of southern of Gabon: comparison of the Pfmdr 1 and Pfert genotypes from symptomatic children. Malar J. 2016;15:420. doi:10.1186/s12936-016-1469-1

21. Pegha Moukandja I, Biteghe Bi Essone JC, Sagara I, et al. Marked rise in the prevalence of asymptomatic plasmodium falciparum infection in rural gabon. PLoS One. 2016;11(5):e0153899. doi:10.1371/ journal.pone. 0153899

22. Zatra R, Lekana-douki JB, Lekoulou F, et al. In vitro antimalarial susceptibility and molecular markers of drug resistance in Franceville, Gabon. BMC Infect Dis. 2012;12:307. doi:10.1186/1471-2334-12-307

23. Pegha-Moukandja I, Charlene Kouna L, Maghendji-Nzdondo S, et al. Pfmdr1 gene polymorphism of Plasmodium falciparum isolates from asymptomatic individuals of Dienga, southeastern Gabon. J Parasit Dis Diagn Ther. 2018;3:18-25. doi:10.4066/2591-7846.1000024

24. Tukwasibwe S, Mugenyi L, Mbogo GW, et al. Differential Prevalence of Transporter Polymorphisms in Symptomatic and Asymptomatic Falciparum Malaria Infections in Uganda. $J$ Infect Dis. 2014;210:154-157. doi:10.1093/infdis/jiu044

25. Ogouyèmi-Hounto A, Ndam NT, Kinde Gazard D, et al. Prevalence of the molecular marker of Plasmodium falciparum resistance to chloroquine and sulphadoxine/pyrimethamine in Benin seven years after the change of malaria treatment policy. Malar J. 2013;12:147. doi:10.1186/1475-2875-12-147

26. Wélé M, Djimdé AA, Guindo A, et al. High frequency of PfCRT 76T in two Malian villages and its prevalence in severe relative to non-severe malaria. Acta Trop. 2011;119(1):11-13. doi:10.1016/j. actatropica.2011.01.002

27. Planche T, Ngou-Milama E, Kremsner PG, et al. Comparison of methods for the rapid laboratory assessment of children with malaria. Am J Trop Med Hyg. 2001;65:599-602. doi:10.4269/ajtmh.2001.65.599

28. Snounou G, Viriyakosol S, Ping Zhu X, et al. High sensitivity of detection of human malaria parasites by the use of nested polymerase chain reaction. Mol Biochem Parasitol. 1993;61:315-320. doi:10.1016/0166-6851(93)90077-B

29. Cox-Singh J, Singh B, Alias A, Abdullah MS. Assessment of the association between three pfmdr1 point mutations and chloroquine resistance in vitro of Malaysian Plasmodium falciparum isolates. Trans R Soc Trop Med Hyg. 1995;89:436-437. doi:10.1016/00359203(95)90045-4

30. Price RN, Cassar C, Brockman A, et al. The pfmdr1 Gene Is Associated with a Multidrug-Resistant Phenotype in Plasmodium falciparum from the Western Border of Thailand Antimicrob. Agents Chemother. 1999;43:2943-2949. doi:10.1128/AAC.43.12.2943

31. Woldearegai TG, Lalremruata A, Nguyen TT, et al. Characterization of Plasmodium infections among inhabitants of rural areas in Gabon. Sci Rep. 2019;9:1-10. doi:10.1038/s41598-019-46194-9

32. Eke RA, Chigbu LN. High Prevalence of Asymptomatic Plasmodium Infection in a Suburb of Aba Town, Nigeria. Ann Afr Med. 2006;5:42-45.

33. Mabunda S, Casimiro S, Quinto L, Alonso P. A country-wide malaria survey in Mozambique. I. Plasmodium falciparum infection in children in different epidemiological settings. Malar J. 2008;7:216. doi:10.1186/1475-2875-7-216

34. Maghendji-Nzondo S, Nzoughe H, Lemamy GJ, et al. Prevalence of malaria, prevention measures, and main clinical features in febrile children admitted to the Franceville Regional Hospital, Gabon. Parasite. 2016;23:32. doi:10.1051/parasite/2016032 
35. Lekana-Douki J-B, Pontarollo J, Zatra R, Toure-Ndouo FS. Paludisme au Gabon: résultats d'une étude bioclinique à l'hôpital de l'amitié sino-gabonaise de Franceville. Cah Détudes Rech Francoph Santé. 2011;21:193-198.

36. Maina RN, Walsh D, Gaddy C, et al. Impact of Plasmodium falciparum infection on haematological parameters in children living in Western Kenya. Malar J. 2010;9:S4. doi:10.1186/1475-2875-9-S3-S4

37. Dokunmu TM, Adjekukor CU, Yakubu OF, et al. Asymptomatic malaria infections and Pfmdr1 mutations in an endemic area of Nigeria. Malar J. 2019;18:218. doi:10.1186/s12936-019-2833-8

38. Nkoghe D, Akue J-P, Gonzalez J-P, Leroy EM. Prevalence of Plasmodium falciparum infection in asymptomatic rural Gabonese populations. Malar J. 2011;10:33. doi:10.1186/1475-2875-10-33

39. Mukomena SE, Philipe CM, Désiré MK, et al. Parasitémie asymptomatique chez les enfants de moins de 5 ans, enfants en âge scolaire et prise en charge des épisodes fébriles dans les ménages de Lubumbashi, République Démocratique du Congo. Pan Afr Med J. 2016;24:94. doi:10.11604/pamj.2016.24.94.9350

40. Rodriguez-Barraquer I, Arinaitwe E, Jagannathan P, et al. Quantification of anti-parasite and anti-disease immunity to malaria as a function of age and exposure. eLife. 2018;7:e35832. doi:10.7554/ eLife.35832

41. Strøm GE, Tellevik MG, Fataki M, Langeland N, Blomberg B. No asymptomatic malaria parasitaemia found among 108 young children at one health facility in Dar es Salaam, Tanzania. Malar J. 2013;12:417. doi:10.1186/1475-2875-12-417

42. Somé AF, Sorgho H, Zongo I, et al. Polymorphisms in K13, pfcrt, pfmdr1, pfdhfr, and pfdhps in parasites isolated from symptomatic malaria patients in Burkina Faso. Parasite. 2016;23:60. doi:10.1051/ parasite/2016069

43. Okombo J, Kamau AW, Marsh K, Sutherland CJ, Ochola-Oyier LI. Temporal trends in prevalence of Plasmodium falciparum drug resistance alleles over two decades of changing antimalarial policy in coastal Kenya. Int J Parasitol Drugs Drug Resist. 2014;4:152-163. doi:10.1016/j.ijpddr.2014.07.003
44. Laufer M, Takala-Harrison S, Dzinjalamala F, et al. Return of chloroquine-susceptible falciparum malaria in Malawi was a reexpansion of diverse susceptible parasites. $J$ Infect Dis. 2010;202:801-808. doi:10.1086/655659

45. Malmberg M, Ngasala B, Ferreira PE, et al. Temporal trends of molecular markers associated with artemether-lumefantrine tolerance/resistance in Bagamoyo district, Tanzania. Malar J. 2013;12:103. doi:10.1186/1475-2875-12-103

46. Sisowath C, Ferreira PE, Bustamante LY, et al. The role of pfmdr1 in Plasmodium falciparum tolerance to artemether-lumefantrine in Africa. Trop Med Int Health. 2007;12:736-742. doi:10.1111/j.13653156.2007.01843.x

47. Baliraine FN, Rosenthal PJ. Prolonged selection of pfmdr1 polymorphisms after treatment of falciparum malaria with artemether-lumefantrine in Uganda. $J$ Infect Dis. 2011;204:1120-1124. doi:10.1093/infdis/jir486

48. Humphreys GS, Merinopoulos I, Ahmed J, et al. Amodiaquine and Artemether-Lumefantrine Select Distinct Alleles of the Plasmodium falciparum mdr1 Gene in Tanzanian Children Treated for Uncomplicated Malaria. Antimicrob Agents Chemother. 2007;51:991-997. doi:10.1128/AAC.00875-06

49. Malmberg M, Ferreira PE, Tarning J, et al. Plasmodium falciparum drug resistance phenotype as assessed by patient antimalarial drug levels and its association with pfmdr1 polymorphisms. J Infect Dis. 2013;207:842-847. doi:10.1093/infdis/jis747

50. Okell LC, Reiter LM, Ebbe LS, et al. Emerging implications of policies on malaria treatment: genetic changes in the Pfmdr-1 gene affecting susceptibility to artemether-lumefantrine and artesunateamodiaquine in Africa. BMJ Glob Health. 2018;3(5):e00999. doi:10.1136/bmjgh-2018-000999

51. Oyakhirome S, Pötschke M, Schwarz NG, et al. Artesunate - amodiaquine combination therapy for falciparum malaria in young Gabonese children. Malar J. 2007;6:29. doi:10.1186/1475-2875-6-29
Infection and Drug Resistance

\section{Publish your work in this journal}

Infection and Drug Resistance is an international, peer-reviewed openaccess journal that focuses on the optimal treatment of infection (bacterial, fungal and viral) and the development and institution of preventive strategies to minimize the development and spread of resistance. The journal is specifically concerned with the epidemiology of antibiotic resistance and the mechanisms of resistance development and diffusion in both hospitals and the community. The manuscript management system is completely online and includes a very quick and fair peerreview system, which is all easy to use. Visit http://www.dovepress.com/ testimonials.php to read real quotes from published authors. 